\title{
Profilicollis altmani (PERRY, 1942) VAN CLEAVE, 1947 (ACANTHOCEPHALA) EN EL PERÚ. CON NOTAS SOBRE LA INFEC- CION EXPERIMENTAL DE MAMÍFEROS TERRESTRES
}

\section{Profilicollis Altmani (PERRY, 1942) VAN CLEAVE, 1947 (ACANTHOCEPHALA) IN PERÚ. WITH NOTES ON THE EXPERIMENTAL INFECTION OF TERRESTRIAL MAMMALS}

\author{
Manuel Tantaleán (*), Jorge Cárdenas (**) y Rosario Güere (**)
}

\begin{abstract}
Resumen
Entre los meses de enero y febrero de 2001, se hizo el estudio parasitológico de Emerita analoga Stimpson (Hippidae) procedentes de la playa Bujama (Mala, Lima), encontrando que de 37 a $48 \%$ de ellos estaban infectados con cistacantos identificados como de Profilicollis altmani (Perry, 1942) Van Cleave, 1947. Estos cistacantos se inocularon en ratas, ratones, hamsters y un cachorro de perro, que resultaron todos infectados. Los parásitos se localizaron principalmente en la cavidad abdominal y/o adheridos a la mucosa del intestino delgado y grueso. El hombre puede infectarse con estos parásitos al ingerir $E$. analoga infectados.
\end{abstract}

\begin{abstract}
A survey was made of sand crab, Emerita analoga Stimpson (Hippidae), collected at Bujama beach (Mala, Lima) January-February, 2001. From 37 to $48 \%$ of them harbored cystacanths identified as Profilicollis altmani (Perry, 1942) Van Cleave, 1947. Otherwise, a number of these cystacanths were inoculated to rats, mice, hamsters and a pup. All animals were infected. The acanthocephalan was found in the abdominal cavity and/or wall of the small and large intestine. Man may become infected with $P$. altmani by eating infected sand crabs.
\end{abstract}

Los acantocéfalos son endoparásitos de vertebrados acuáticos y terrestres de los cuales son pocas las especies que infectan accidentalmente al hombre (Schmidt, 1971). En el Perú no se conocía la infección humana con estos parásitos hasta la publicación del trabajo de Ibáñez y Machado (1991), en donde se menciona el hallazgo, en la ciudad de Trujillo, de 4 personas infectadas con Falsifilicollis sphaerocephalus, estos casos son considerados los primeros en el mundo donde un

$\left(^{*}\right)$ Profesor invitado. Laboratorio de Parasitología. Facultad de Ciencias y Filosofía. Universidad Peruana Cayetano Heredia, Lima, Perú. Email: mtantaleanv@hotmail.com

${ }^{(* *}$ Laboratorio de Parasitología. Facultad de Ciencias y Filosofía. Universidad Peruana Cayetano Heredia. Lima, Perú. acantocéfalo de ave puede infectar de manera natural a un mamífero terrestre como el hombre.

Recientemente, nosotros hemos identificado a Profilicollis altmani (Perry, 1942) Van Cleave, 1947; cuyo estadio adulto se desarrolla en el intestino de diversas aves marinas, entre ellas Larus pipixcan Wagler "gaviota de Franklin", ave migratoria que proviene del Hemisferio Norte y el cistacanto en Emerita analoga Stimpson ("muy-muy") (Ver descripción en Nickol et al., 2002.)

El objetivo del presente trabajo fue conocer si Profilicollis altmani, identificado por primera vez en el Perú, puede infectar a vertebrados terrestres $\mathrm{y}$ en que órganos se localiza. 
Se utilizaron 4 hámsteres dorados, 4 ratones blancos Swiss, 5 ratas albinas y 1 perro, este último de 1 mes de edad. A cada uno de los 3 primeros animales se les inoculó por vía oral un promedio de 20 cistacantos identificados como de Profilicollis altmani recientemente extraídos de E. analoga procedentes de la playa Bujama (provincia de Mala, Lima), el perro recibió una dosis de 60 cistacantos, algunos de ellos evaginados. Los animales fueron sacrificados con sobredosis de cloroformo desde el tercer día hasta los 15 días de infección, excepto el perro que se sacrificó a los 6 días. Los parásitos y los órganos afectados que se obtuvieron se fijaron en formol al $10 \%$, los gusanos se colorearon con carmín de Semichon y montaron en bálsamo para observaciones morfológicas y mediciones.

Todos los animales se infectaron con no menos del $80 \%$ de los cistacantos inoculados, los parásitos se localizaron en el mesenterio, pared interna del abdomen, riñones y vejiga; en algunos casos se encontraron cubiertos por una membrana formada por el huésped. Sólo en el perro el $10 \%$ de los parásitos también se localizó en la mucosa del intestino delgado y grueso.

En todos los casos los parásitos sufrieron cambios en la forma del cuerpo y mayor desarrollo de los órganos internos. Así, en las ratas, ratones y hámsteres los acantocéfalos aumentaron de tamaño hasta alcanzar $6 \mathrm{~mm}$ de longitud con modificación de la forma de la trompa, de cilíndrica que se presenta en el cistacanto a globular que caracteriza a los adultos; los órganos sexuales tuvieron muy poco desarrollo aún en las formas recuperadas a los 15 días de la inoculación.

En el perro, todos los gusanos recuperados alcanzaron mayor longitud, $1 \mathrm{~cm}$, especialmente los que se localizaron en la mucosa intestinal; también mostraron cambios morfológicos como alargamiento del cuerpo y la esfericidad de la trompa. En los especímenes coloreados se pudo apreciar morfogénesis avanzada, con aumento del ta- maño de los testículos en los machos pero sin llegar a la espermatogenesis, desarrollo de las glándulas de cemento y del receptáculo seminal que a su vez se encontraba distendido y lleno de una sustancia; y en las hembras, desarrollo del ovario incluso con formación de las masas ováricas. No se observaron huevos debido al tiempo de desarrollo del parásito.

En el Perú, Ibáñez y Machado (1991) dieron a conocer el hallazgo de 4 casos de infección humana por acantocéfalos que identificaron como Falsifilicollis sphaerocephalus. En un trabajo reciente, Nickol et al. (1999) han considerado el género Falsifilicollis como sinónimo de Profilicollis. La especie Profilicollis sphaerocephalus (Bremser in Rudolphi, 1819) tiene, entre otras características, 6 glándulas de cemento, infecta a aves marinas que provienen de Australia, Tasmania, etc., y los huéspedes intermediarios son crustáceos decápodos de las familias Grapsidae y Portunidae. Los detalles morfológicos de los especímenes y los dibujos presentados por Ibáñez y Machado muestran características que lo asemejan a P. altmani. Adicionalmente, en nuestro país no se ha reportado el hallazgo de cistacantos en cangrejos Grapsidae o Portunidae; por estas consideraciones creemos que los especímenes reconocidos por Ibañez y Machado corresponden a P. altmani. En 1982, Mateo et al. describieron el adulto de una nueva especie de acantocéfalo, Polymorphus (Profilicollis) bullocki así como el estadio de cistacanto obtenido de Emerita analoga. Aunque no hemos observado el material tipo, es posible que esta especie sea sinónima de $P$. altmani.

Reish (1950) infectó 5 ratas con cistacantos de Polymorphus kenti Van Cleave, 1947 (=Profilicollis altmani) y recuperó en 4 de ellas especímenes inmaduros adheridos al intestino cuyas dimensiones coinciden con las de nuestros parásitos. En el medio natural, específicamente en la costa central de California (EE. UU de Norteamérica), se ha visto que Profilicollis 
altmani produce serias lesiones o la muerte de la nutria marina Enhydra lutris (Hennessy y Morejohn, 1977). La penetración de la pared intestinal puede explicarse por los resultados de los estudios de Polzer y Taraschewski (1994), quienes han encontrado que algunos acantocéfalos que lesionan profundamente el tejido intestinal elaboran enzimas proteolíticas que pueden tener relación con la degradación de los componentes del tejido del huésped.

Los resultados que hemos obtenido indican que $P$. altmani tiene una gran capacidad de infección y que puede localizarse o penetrar la pared intestinal de vertebrados terrestres debido a su alta inespecificidad, de esta manera se puede explicar la infección humana en nuestro medio y la escasa recuperación de estadios adultos. Creemos que la principal localización del parásito en el hombre es extraintestinal como ocurre en el perro, pero cuando éste se localiza en el intestino probablemente no madura; por lo tanto, ante la imposibilidad de encontrar huevos, el diagnóstico de la infección requerirá de pruebas inmunoserológicas que será necesario desarrollar.

Uno de los crustáceos que abunda en las playas arenosas del litoral peruano y que se utiliza como alimento humano como "cebiche" es Emerita analoga, huésped intermediario de $P$. altmani. Algunos trabajos relacionados con la presencia de cistacantos de P. bullocki (¿Profilicollis altmani) en el huésped intermediario E. analoga en algunas playas de la costa peruana establecen el alto porcentaje de infección de estos crustáceos (Alvitres et al., 1999). Nosotros hemos visto que en la playa Bujama (Enero-Febrero, 2001) entre 37\% y $48 \%$ de estos crustáceos estaban infectados con una carga parasitaria de hasta 9 especímenes por animal. Estos hallazgos convierten al "muy - muy" en un alimento peligroso para la salud del hombre si se ingiere insuficientemente cocido o si los componentes del "cebiche" no afectan la viabilidad del parásito.
A pesar de la importancia que adquiere este parásito en la salud del hombre, no se han realizado estudios para conocer aspectos relacionados con la prevalencia, patogenicidad, resistencia del parásito y diagnóstico de la infección.

\section{Literatura citada}

Alvitres, V., J. Chanamé, J. Fupuy, A. Chambergo y M. Cortez. 1999. Cambios en la prevalencia de los helmintos parásitos de Emerita analoga por efecto de "El Niño 1997-98”. En: El Niño 1997-98 y su impacto sobre los ecosistemas marino y terrestre. J. Tarazona y E. Castillo (Eds.). Rev. Peru. Biol. Vol. Extraordinario: 6976.

Hennessy, S.L and V. Morejohn. 1977. Acanthocephalan parasites of the sea otter, Enhydra lutris, off coastal California. Calif. Fish. Game, 63: 268272.

Ibañez, H.N. y F.D.A. Machado. 1991. Infección humana con Falsifilicollis sphaerocephalus (Acanthocephala) en Trujillo, Perú. Rev. Per. Med. Trop. UNMSM., 5: 75-78.

Mateo, E., R. Córdova y E. Guzmán. 1982. Polymorphus (Profilicollis) bullocki, nueva especie de acantocéfalo en la gaviota Larus belcheri, en el Perú. Bol. de Lima, 4: 73-78.

Nickol, B.N., D.W.T. Crompton. and D.W. Searle. 1999. Reintroduction of Profilicollis Meyer, 1931, as a genus in Acanthocephala: significance of the intermediate host. J. Parasitol., 85: 716718 .

Nickol, B.N., R.W. Heard and N.F. Smith. 2002. Acanthocephalans from crabs in the southeastern U.S., with the first intermediate hosts known for Arhythmorhynchus frassoni and Hexaglandula corynosoma. J. Parasitol., 88: 79-83.

Polzer, M. and H. Taraschewski. 1994. Proteolytic enzymes of Pomphorhynchus laevis and in three other acanthocephalan species. J. Parasitol., 80: 45-49.

Reish, D. J. 1950. Preliminary note on the life cycle of the acanthocephalan, Polymorphus kenti Van Cleave, 1947. J. Parasitol., 36: 496.

Schmidt, G.D. 1971. Acanthocephalan infections of man, with two new records. J. Parasitol., 57: 582584 . 